\title{
Armazenamento de crisântemos brancos sob condição ambiente utilizando soluções conservantes
}

\author{
Storage of white chrysanthemum under room conditions using \\ preservative solutions
}

\author{
Leirson Rodrigues da Silva ${ }^{1 *}$; Silvanda de Melo Silva ${ }^{2}$
}

\section{Resumo}

O objetivo deste trabalho foi avaliar o efeito de soluções conservantes na manutenção da qualidade póscolheita de flores de crisântemo (Dendranthema grandiflora T.) do tipo branco, variedade Calábria. As flores foram mantidas à temperatura ambiente, de $24 \pm 2^{\circ} \mathrm{C}$ e $85 \pm 2 \%$ UR, nos seguintes tratamentos: água destilada (controle), solução de hipoclorito de sódio (80ppm e $800 \mathrm{ppm})$, solução de sacarose $(10 \%$ e $15 \%)$ e solução de hidroxiquinolina $(0.04 \%$ e $0.08 \%)$. As flores permaneceram dezoito dias no ambiente de armazenamento, sendo as soluções substituídas a cada quatro dias. Foram realizadas as seguintes avaliações: longevidade (notas de 0-4), aparência (notas de 1-9). As soluções de hipoclorito de sódio a $80 \mathrm{ppm}$ e $800 \mathrm{ppm}$ reduziram a longevidade de crisântemos brancos, comparadas ao controle. A utilização de soluções de hidroxiquinolina a $0.04 \%$ e $0.08 \%$ não contribuiu no prolongamento da longevidade ou manutenção da boa aparência das flores. Conclui-se que a solução conservante à base de sacarose a $10 \%$ manteve a vida útil pós-colheita durante 17 dias, proporcionando menor percentual de flores com manchas escuras e menores danos às sépalas e folhas.

Palavras-chave: Hipoclorito de sódio, hidroxiquinolina, sacarose, pós-colheita, Dendranthema grandiflora $\mathrm{T}$.

\begin{abstract}
The objective of this work was to evaluate the effect of preservative solutions on the maintenance of postharvest quality of white type chysanthemum flowers (Dendrathema grandiflora T.). Flowers were kept at room temperature $\left(24 \pm 2{ }^{\circ} \mathrm{C}\right.$ and $\left.85 \pm 2 \% \mathrm{UR}\right)$, under the following treatments: distilled water (control); sodium hypochloride solutions (80ppm and $800 \mathrm{ppm})$; sucrose solutions (10\% and $15 \%$ ) and hidroxyquinoline solutions $(0.04 \%$ and $0.08 \%)$. Flowers were stored under these treatments during 18 days, being the solutions changed each 4 days. The following evaluations were done: longevity (scores from 0 to 4), flower appearance (scores from 1 to 9). Sodium hipochloride solutions at $80 \mathrm{ppm}$ and $800 \mathrm{ppm}$ reduced white chrysanthemum longevity as compared to control. The utilization the hidroxyquinoline solutions at $0.04 \%$ and $0.08 \%$ had no effects on flower longevity or quality maintenance. The preservative solution utilizing $10 \%$ of sucrose kept the postharvest quality during 17 days, providing flowers with lower percentage of dark spots, and lower index of petals and leaves damage.

Key words: Sodium hypochloride, hidroxyquinoline, sucrose, postharvest, Dendranthema grandiflora $\mathrm{T}$.
\end{abstract}

\footnotetext{
1 Aluno do Programa de Pós-Graduação em Fitotecnia (UFERSA-RN). Departamento de Ciências Vegetais, Mossoró-RN. E-mail: leirsonrodrigues@yahoo.com.br.

2 Professor adjunto, Ph.D, Departamento de Ciências Fundamentais e Sociais, Centro de Ciências Agrárias, Campus II, Areia, Paraíba. E-mail: silvasil@cca.ufpb.br

* Autor para correspondência
} 


\section{Introdução}

A floricultura abrange o cultivo de plantas ornamentais, desde flores de corte e plantas envasadas, floríferas ou não, até a produção de sementes e mudas de árvores de grande porte. É um setor competitivo, que exige utilização de técnicas avançadas, conhecimento técnico pelo produtor e sistema eficiente de distribuição e comercialização (SILVEIRA, 1993).

O mercado mundial de flores e plantas ornamentais está em fase de expansão. Com a globalização, novas regiões de produção foram se firmando em todo o mundo, principalmente nas regiões com clima favorável e com disponibilidade de mão de obra. Entre os novos países produtores, passaram a se destacar: Colômbia, Equador, Costa Rica, Estados Unidos, Israel, África do Sul, Quênia, Espanha e Brasil. A produção mundial de flores e plantas ornamentais ocupa uma área estimada de 190.000 hectares, movimentando valores próximos a 16 bilhões de dólares por ano, em termos de produtor, ou de 44 bilhões de dólares anuais, considerando a venda no varejo, para o consumidor final. Atualmente, os maiores produtores mundiais são a Holanda, os Estados Unidos e o Japão. No Brasil o estado de São Paulo é o maior produtor, com cerca de $60-70 \%$ do total negociado no país (UPNMOOR, 2003).

Entre os principais problemas que a floricultura brasileira tem que superar está o manejo póscolheita inadequado. Ainda faltam conhecimento e tecnologias de colheita e pós-colheita que visem à redução de perdas, que no Brasil chegam atingir 40\% da produção (DIAS-TAGLIACOZZO; CASTRO, 2002). Assim, o abastecimento contínuo e com qualidade, deve ser uma preocupação constante dos produtores de flores durante todas as fases do processo produtivo.

Segundo Junqueira e Peetz(2004), os crisântemos em vasos apresentam posição de destaque entre as plantas mais vendidas nos três maiores mercados nacionais (terceiro lugar na CEASA Campinas, quinto no Veiling Holambra e sétimo na CEAGESPSP), sendo o valor global da comercialização atacadista de crisântemo em vaso, no Estado de São Paulo, avaliado entre R\$15 milhões e R\$ 20 milhões.

De acordo com Grusznski (2001), o crisântemo é umhíbrido complexo que, se produzido por sementes, segrega em formas diversas. A maioria das espécies que compõem as linhagens das cultivares atuais é originaria da Ásia, em especial da China. A palavra crisântemo significa "flor dourada", vindo do grego "chrysos", ouro, e "anthemon", flor. Existem relatos de seu cultivo há mais de 2000 anos como planta de jardim na Ásia, sendo ela a flor nacional do Japão.

A longevidade das flores é resultante de vários fatores pré e pós-colheita e está relacionada com características genéticas, fisiológicas e anatômicas de cada espécie e entre cultivares (MORAES et al., 1999). O armazenamento de flores visa basicamente minimizar os problemas de conservação, transporte e distribuição, com o objetivo de reduzir o processo de senescência, aumentando a longevidade (SEREK, 1993).

A aplicação conjunta ou separadamente de tratamento com produtos químicos no manejo póscolheita geralmente melhora a longevidade e o período de comercialização, sobretudo em condições onde o acesso à refrigeração é limitado. As soluções conservantes devem possuir composição necessária para fornecer energia às flores, bloqueando o desenvolvimento microbiano ou a síntese de etileno (BELLÉ, 2000).

O presente trabalho teve como objetivo avaliar o efeito de soluções preservativas na conservação pós-colheita de crisântemos mantidos sob condição ambiente.

\section{Material e métodos}

Crisântemos brancos (Dendranthema grandiflora T.) da variedade Calábria foram colhidos no campo de cultivo comercial daCooperativa dos Floricultores 
do Estado da Paraíba (COFEP), Sítio Avarzeado no Município de Pilões-PB, localizado na microrregião do Brejo Paraibano com altitude de $334 \mathrm{~m} \mathrm{e}-06^{\circ} 42^{\prime}$ $00^{\prime}$ de latitude. As flores foram colhidas pela manhã, no ponto de colheita comercial e transportadas para o laboratório de Biologia e Tecnologia Pós-colheita, do Departamento de Ciências Fundamentais e Sociais (DCFS), do Centro de Ciências Agrárias CCA/ UFPB, Areia - PB.

Realizou-se inicialmente a eliminação da folhagem basal e corte da base da haste floral dentro d'água, sendo estas uniformizadas com aproximadamente $50 \mathrm{~cm}$ de comprimento e selecionadas quanto ao ponto de colheita (flores totalmente abertas ou próximas da abertura total). Os tratamentos avaliados foram soluções de sacarose (10\% e 15\%), hipoclorito de sódio (80ppm e $800 \mathrm{ppm})$, hidroxiquinolina $(0,04 \%$ e $0,08 \%)$ e controle (água destilada), armazenados em condição ambiente $\left(24 \pm 2{ }^{\circ} \mathrm{C}\right.$ e $85 \pm 2 \%$ UR). As soluções foram substituídas a cada quatro dias, quando a base da haste era cortada, na região obstruída.

O experimento foi conduzido em delineamento inteiramente casualizado, com sete tratamentos, quatro repetições, com uma haste cada, aproximadamente oito flores por haste. As avaliações foram realizadas diariamente, durante 18 dias, até a inviabilização para comercialização ou senescência das flores, por meio dos parâmetros:

Longevidade (nota de $0-4$ ) em que: $0-0 \%$ de abscisão ou morte de pétalas; $1-15 \% ; 2-30 \%$; $3-50 \%$ e $4 \geq 50 \%$, tomando-se como referência o número de dias, a partir da colheita, nos quais não apresentaram abscisão ou morte de pétalas;

Aparência (nota de 1-9): 1 - Inaceitável; 3 Ruim; 5 - Regular; 7 - Bom; 9 - Excelente.

\section{Em que:}

1- Senescência completa da flor, com murchamento, escurecimento pronunciado das pétalas, senescência completa das pétalas, haste escurecida, imprestável para comercialização;

3- Murchamento acentuado, presença de manchas nas pétalas e hastes, injúrias pronunciadas, enrugamento e escurecimento evidente das pétalas;

O grau 4 indicava o limite de aceitação da flor quando era observada perda do valor ornamental e comercial.

5- Início de murchamento, aparência ligeiramente atrativa, ausência de manchas e injúrias e/ou enrugamento;

7-Flor fresca, túrgida, ligeiro murchamento, ausência de manchas e injúrias, ausência de enrugamento;

9- Flor fresca, túrgida, isenta de injúrias, muito atrativa, perfeita para exposição em vasos.

Os dados foram submetidos à análise de variância (ANOVA), e nas médias dos fatores quantitativos, fez-se análise de regressão.

\section{Resultados e discussão}

A longevidade das flores até o sexto dia não apresentou diferença significativa entre os tratamentos; entretanto, a partir do sétimo dia de armazenamento, flores mantidas em solução de 800ppm de hipoclorito de sódio apresentaram menor longevidade até o final do armazenamento, quando comparado aos demais tratamentos (Figura 1). 

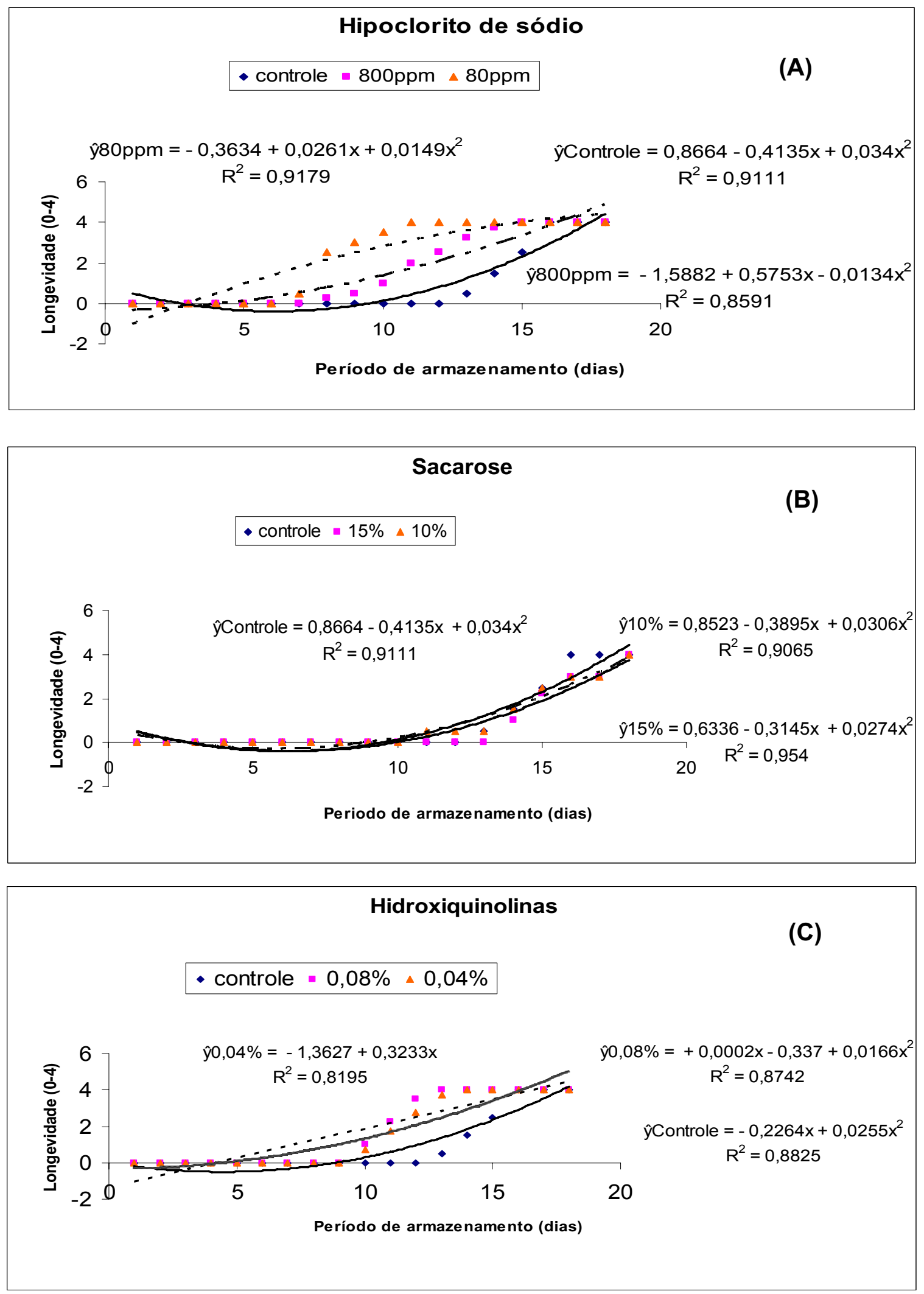

Figura 1. Notas para longevidade de hastes de crisântemos brancos mantidas em soluções de hipoclorito de sódio (80ppm e $800 \mathrm{ppm})(\mathrm{A})$, sacarose (10\% e $15 \%)(\mathrm{B})$, hidroxiquinolina $(0.04 \%$ e $0.08 \%)$ (C) e água destilada (controle), em condição ambiente $\left(24 \pm 2{ }^{\circ} \mathrm{C}\right.$ e $85 \pm 2 \%$ UR). 
Alongevidade média de crisântemos foi de 17, 14 e 12 dias, para flores mantidas nas soluções de $10 \%$ e $15 \%$ de sacarose e controle, respectivamente. $\mathrm{O}$ murchamento das flores foi o sintoma mais evidente da senescência, não havendo abscisão das pétalas e das folhas até 11 dias após a colheita, o que foi inicialmente observado para o tratamento $80 \mathrm{ppm}$ de hipoclorito de sódio. No entanto, para o tratamento com 800ppm de hipoclorito de sódio não houve abscisão. No oitavo dia de armazenamento, as flores apresentavam-se inviáveis para comercialização, atingindo perdas de mais de $50 \%$ de flores a partir do décimo primeiro dia. Até o nono dia, as flores mantidas em soluções de hidroxiquinolina (8-HQ) a $0.04 \%$ e $0.08 \%$ não apresentavam índices de abscisão ou morte de pétalas; entretanto, a partir do décimo dia, estas flores tenderam a apresentar menor longevidade, comparadas aquelas com sacarose. No décimo quinto dia de armazenamento, observou-se perda de mais de $50 \%$ de flores, as quais tornaramse totalmente inaceitáveis para comercialização. Com isso, a utilização de $0.04 \%$ e 0.08 \% de 8 -HQ nas soluções de manutenção não foi eficiente no prolongamento da longevidade e manutenção da qualidade floral.

Os tratamentos utilizando soluções à base de sacarose proporcionaram maior longevidade a crisântemos brancos durante o período de armazenamento, cujas hastes florais apresentaram maior vida útil e floração mais prolongada. Quando comparadas com crisântemos mantidos somente em água destilada (controle), a longevidade aumentou em até cinco dias. Outro benefício da adição de sacarose foi o fato de que esta permitiu que as flores se desenvolvessem completamente, oquenãoaconteceu quando utilizou-se somente água. Aparentemente, a maior longevidade pode estar associada a peso fresco constante e aumento no peso seco. Segundo Klougart (1967), Lukaszewska (1980), Arriaga e Guerrero (1995), a melhor concentração de açúcar para crisântemo seria a sacarose de $5 \%$ a $20 \%$. No presente trabalho, no entanto, a sacarose adicionada a $10 \%$ foi à condição mais eficiente em prolongar a longevidade média das flores e diminuir o percentual de flores com manchas escuras nas sépalas e folhas, até 17 dias de armazenamento. O efeito benéfico da utilização da sacarose no prolongamento da longevidade foi também demonstrado em rosas por Castro, Vidigal e Garcia (1979). A aparência das flores se manteve acima do limite de aceitação para crisântemos mantidos em solução de sacarose, com melhor aparência das flores com relação aos demais tratamentos até o décimo quinto dia de armazenamento para $15 \%$ e até o décimo sétimo dia para $10 \%$ de sacarose. Observou-se ainda que as hastes colocadas apenas em água destilada obtiveram nota 7 até o décimo quarto dia, o que caracterizou aparência comercial muito boa, indicando que a sua imersão em água é suficiente para ampliação da vida útil pós-colheita por duas semanas.

Correlacionando a longevidade de algumas flores de corte com o seu nível de carboidratos, Rogers (1973) deduziu que possivelmente as flores cortadas durante o período vespertino seriam mais duráveis que aquelas cortadas matutinamente, devido à fotossíntese.

Verificou-se também que as hastes tratadas com hipoclorito de sódio a $800 \mathrm{ppm}$ foram as que apresentaram, já a partir do sexto dia de armazenamento, aparência não comercial, estando inaceitáveis a partir do décimo quarto dia de armazenamento (Figura 2). 

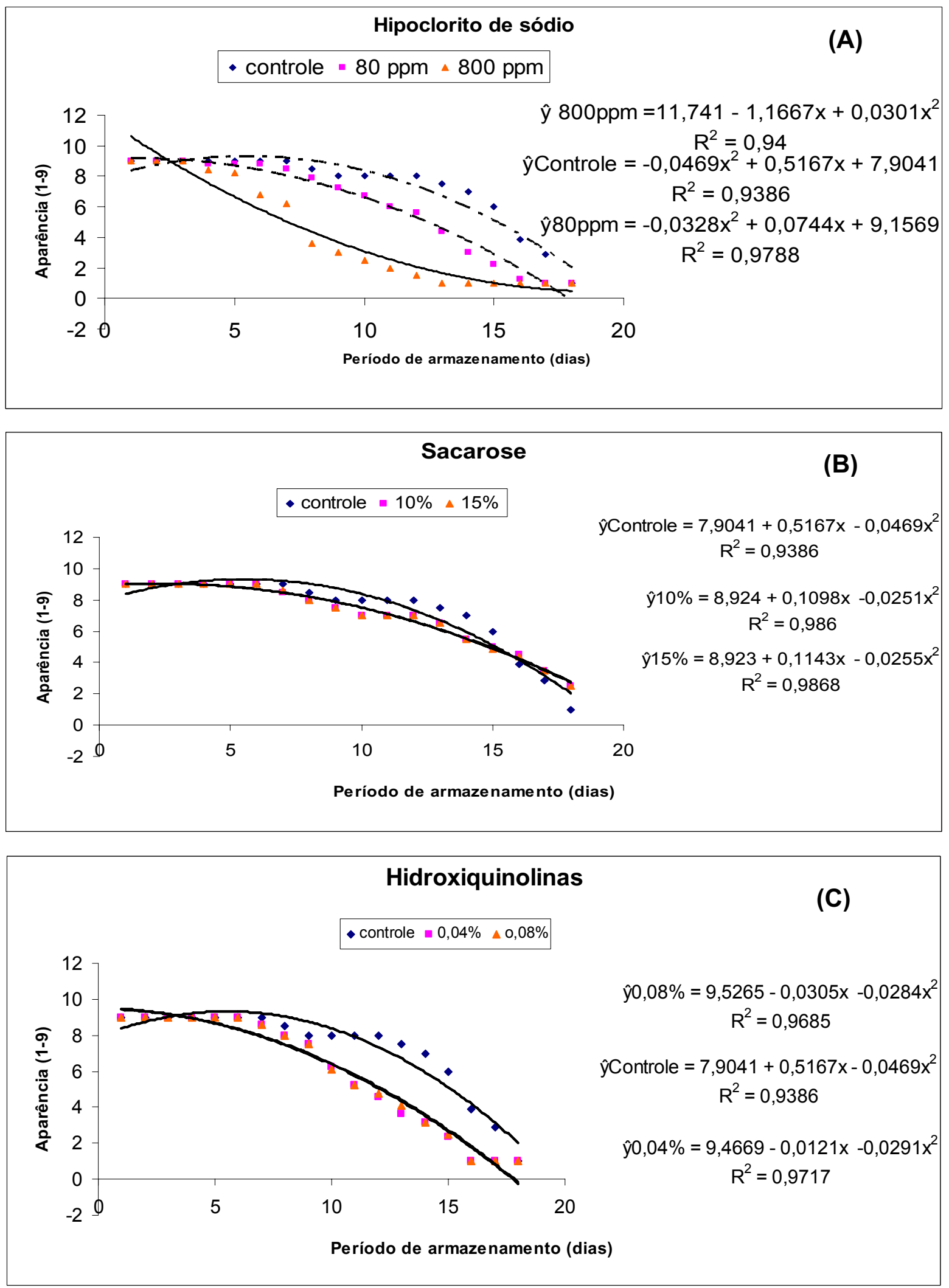

Figura 2. Notas para aparência de hastes de crisântemos brancos mantidas em soluções de hipoclorito de sódio (80ppm e $800 \mathrm{pm})(\mathrm{A})$, sacarose (10\% e 15\%) (B), hidroxiquinolina (0.04 e 0.08\%) (C) e água destilada (controle), em condição ambiente $\left(24 \pm 2{ }^{\circ} \mathrm{C}\right.$ e $85 \pm 2 \%$ UR). 
Até o nono dia de armazenamento, as flores mantidas em soluções de hidroxiquinolina apresentavam boa aparência comercial; no entanto, a partir daí começaram a apresentar índices de queda, já chegando ao décimo quinto dia com aparência considerada ruim. Com isso, o uso de hidroxiquinolina não foi eficiente na melhor aparência das flores.

Castro et al. (1987) sugerem que o uso de inibidores microbianos, como o 8-HQ, deve ser associado a outros ingredientes em soluções conservantes, para melhor expressão de seus efeitos benéficos. A senescência das folhas se manifestou através de uma seqüência de eventos ao longo do armazenamento: primeiro, ocorreu escurecimento; segundo, murchamento; terceiro, escurecimento da base da haste, seguido do amarelecimento e, quarto, terminando com a necrose foliar. Com o aumento do período de armazenamento ocorreu aceleração no aparecimento de danos nas folhas. $\mathrm{O}$ surgimento de necroses marginais em folhas de crisântemo cv. Albatroz foram relacionadas ao prolongamento do período de armazenamento (KOFRANEK; HALEVY; KUBOTA, 1975). Trabalhando com rosas, Faragher e Mayak (1984) observaram que a senescência é muito mais lenta à baixa temperatura e sofre uma aceleração quando se transfere as flores para temperatura ambiente. Estes autores sugeriram que o estímulo à produção de etileno, após a transferência da refrigeração para temperatura ambiente, pode ter efeito direto da exposição à baixa temperatura de armazenamento.

\section{Conclusões}

O tratamento com sacarose proporciona maior manutenção da qualidade das flores de crisântemos brancos, melhor aparência, longevidade e manutenção da vida útil por até 17 dias, com qualidade comercial;

A utilização de $800 \mathrm{ppm}$ de hipoclorito de sódio impede a queda das pétalas, no entanto provoca o murchamento e escurecimento das flores;

A utilização de $0.04 \%$ e $0.08 \%$ de 8 -HQ não prolonga a longevidade e/ou manutenção da qualidade floral de crisântemos brancos;

A sacarose a 10\% inibe a ocorrência de escurecimento da base da haste e aumenta a conservação de crisântemos brancos, mantidos sob condição ambiente.

\section{Referências}

ARRIAGA, N. R. M.; GUERRERO, J. E. Effect of preservative solutions on the vase life of cut flowers of chrysanthemun "Polaris" under two environmental conditions. Efecto de diferentes soliciones preservativas em la vida de florero de tallos florales de "Polaris" bajo dos condiones ambientales. Revista Chapingo, Tepic, México, v. 3, n. 1, p. 103-107, Serie Horticultura. 1995.

BELLÉ, R. A. Caderno didático de floricultura: flores de jardim, curso de agronomia. Santa Maria: UFSM. 128 p. 2000.

CASTRO, C. E. F.; VIDIGAL, J. C.; GARCIA, J. L. M. Efeito de preservativos florais na durabilidade de três cultivares de rosa. In: CONGRESSO DA SOCIEDADE BRASILEIRA DE FLORICULTURA E PLANTAS ORNAMENTAIS, 1.; Viçosa. Anais... Viçosa: Fundação Cargill, p. 144-158. 1979.

CASTRO, C. E. F; LUCHESI, A. A.; CASTRO, J. V; ZULLO, M. A; MORAES, P. J. Manutenção da qualidade pós-colheita de cravo Scania Red Sim, II. Efeitos do thiabendazole e da 8-hidroxiquinolina. In: CONGRESSO BRASILEIRO DE FLORICULTURA E PLANTAS ORNAMENTAIS, n. 4, 1987. Campinas. Anais...Campinas: Fundação Cargill, p. 159-170. 1987.

DiAS-TAGLiACOZZO, G. M.; C ASTRO, C. E. F. Fisiologia pós-colheita de espécies ornamentais. In: WACHOWICZ, C. M.; CARVALHO, R. I. N. (Org.). Fisiologia vegetal: produção e pós-colheita. Curitiba: Champagnat, p. 359-382 (Coleção agrárias). 2002.

FARAGHER, J. D.; MAYAK, S. Physiological responses of cut rose flowers to exposure to low temperature: change in membrane permeability and ethylene production. J. Exp. Bot, Austrália, v. 35, n. 156. p. 956-974, 1984.

GRUSZNSKI, C. Produção comercial de crisântemos: vaso, corte e jardim. Guaíba: Agropecuária. Guaíba, RS, 2001. 
JUNQUEIRA, A. H.; PEETZ, M. S. Crisântemos hoje e sempre: tecnologia de produção. Revista Brasileira de Horticultura Ornamental, Conchal, v. 26, n. 227, p. 2527. 2004.

KLOUGART, A. Cut flower keeping quality test in Denmark. Zierpflanzenbau, Berlim, v. 1, n. 7, p. 565-566, 1967.

KOFRANEK, A. M.; HALEVY, A. H. KUBOTA, J. Bud opening of chrysanthemus after long ter storage. Hortscience, Alexandria, v. 10, n. 4, p. 378-380, 1975.

LUKASZEWSKA, A. J. Effect of the preservative solution on keeping qualities of the new Diana carnations. Annals of Warsaw Agricultural University SGGW, Horticulturae, New York, v. 1, n. 17, p. 25-30, 1980.

MORAES, P. J.; CECON, P. B.; FINGER, F. L.; BARBOSA, J. G.; ALVARES, V. S. Efeito da refrigeração e do condicionamento em sacarose sobre a longevidade de inflorescências de Strelitzia reginae Ait. Revista Brasileira de Horticultura Ornamental, Campinas, v. 5, n. 2, p. 151-156, 1999.

ROGERS, M. N. An historical review of postharvest physiology research on cut flowers. HortScience, Alexandria, v. 8, n. 3, p. 189-194, 1973.

SEREK, M. Ethephon and silver thiosulfate affect postharvest characteristics of rosa hybrida Victory Parade. Hort Science, Alexandria, v. 8, n. 10, p. 199-2000. 1993.

SILVEIRA, R. B. A. Situação da floricultura no Brasil. Net. 1993. Disponível em: <http://www.uesb.br>. Acesso em: 23 ago. 2006.

UPNMOOR, M. S. I. Cultivo de plantas ornamentais. In: UPNMOOR, M. S. I. Produção de flores. Guaíba: Editora Agropecuária, 2003, p. 11-14. (Biblioteca da terra, 3). 